\title{
Carbyne Polysulfide as a Novel Cathode Material for Rechargeable Magnesium Batteries
}

\author{
Yanna NuLi, ${ }^{1,2}$ Qiang Chen, ${ }^{1,2}$ Weikun Wang, ${ }^{3}$ Ying Wang, ${ }^{4}$ Jun Yang, ${ }^{1,2}$ and Jiulin Wang ${ }^{1,2}$ \\ ${ }^{1}$ Department of Chemical Engineering, Shanghai Jiao Tong University, Shanghai 200240, China \\ ${ }^{2}$ Hirano Institute for Materials Innovation, Shanghai Jiao Tong University, Shanghai 200240, China \\ ${ }^{3}$ Research Institute of Chemical Defense, West Building, No. 35 Huayuanbei Road, Beijing 100083, China \\ ${ }^{4}$ Key Laboratory for Thin Film and Microfabrication of the Ministry of Education, \\ Shanghai Jiao Tong University, Shanghai 200240, China \\ Correspondence should be addressed to Yanna NuLi; nlyn@sjtu.edu.cn and Weikun Wang; wangweikun2002@163.com
}

Received 12 August 2013; Accepted 24 October 2013; Published 21 January 2014

Academic Editors: A. Avramopoulos and J. K. Singh

Copyright (C) 2014 Yanna NuLi et al. This is an open access article distributed under the Creative Commons Attribution License, which permits unrestricted use, distribution, and reproduction in any medium, provided the original work is properly cited.

We report the formation of carbyne polysulfide by coheating carbon containing carbyne moieties and elemental sulfur. The product is proved to have a $\mathrm{sp}^{2}$ hybrid carbon skeleton with polysulfide attached on it. The electrochemical performance of carbyne polysulfide as a novel cathode material for rechargeable magnesium batteries is firstly investigated. The material exhibits a high discharge capacity of $327.7 \mathrm{mAh} \mathrm{g}^{-1}$ at $3.9 \mathrm{~mA} \mathrm{~g}^{-1}$. These studies show that carbyne polysulfide is a promising candidate as cathode material for rechargeable $\mathrm{Mg}$ batteries if the capacity retention can be significantly improved.

\section{Introduction}

It is well known that one of the greatest challenges of modern electrochemistry is the development of high energy density, rechargeable batteries for applications such as electric vehicles and large-scale power storage systems. Rechargeable magnesium battery system with magnesium anode may provide an alternative candidate that is competitive with post Li-ion batteries containing a lithium metal anode due to a relatively low price $(\$ 2700 /$ ton and $\$ 64,800 /$ ton for $\mathrm{Mg}$ and $\mathrm{Li}$, resp.), a high theoretical volumetric capacity $\left(3,832 \mathrm{mAh} \mathrm{cm}^{-3}\right.$ for $\mathrm{Mg}$ and $2,062 \mathrm{mAh} \mathrm{cm}^{-3}$ for $\left.\mathrm{Li}\right)$, and a higher expected safety (less dendritic morphologies for magnesium deposits than lithium) for magnesium compared with lithium $[1,2]$. In 2000, a prototype with $\mathrm{Mg}_{x} \mathrm{Mo}_{6} \mathrm{~S}_{8}(0<$ $x<2)$ cathode and $\mathrm{Mg}\left(\mathrm{AlCl}_{2} \mathrm{EtBu}\right)_{2} / \mathrm{THF}(\mathrm{Bu}=$ butyl, $\mathrm{Et}=$ ethyl) electrolyte described by Aurbach et al. paves the way for the realization of rechargeable magnesium batteries [3]. Over the years, there have been continuous efforts in developing electrolyte systems with a wider electrochemical window and alternative cathode materials with a higher capacity and voltage plateau [4-12].
Compared with similarly sized and monovalent $\mathrm{Li}^{+}$ion, $\mathrm{Mg}^{2+}$ ion has a stronger polarization due to the bivalence. A fundamental challenge of magnesium intercalation in inorganic hosts is the difficulty of $\mathrm{Mg}^{2+}$ insertion and the slow kinetics of $\mathrm{Mg}^{2+}$ diffusion $[13,14]$. We proposed a class of energy storage materials, organosulfur compounds with S-S bonds, that is, 2,5-dimercapto-1,3,4-thiadiazole (DMcT), poly-2,2' dithiodianiline (PDTDA), and a conductive sulfur-containing material (CMS), as novel cathode materials for rechargeable magnesium batteries [15]. The capacity of the organosulfur compounds in $0.25 \mathrm{~mol} \mathrm{~L}^{-1}$ $\mathrm{Mg}\left(\mathrm{AlCl}_{2} \mathrm{EtBu}\right)_{2} / \mathrm{THF}$ was low and decayed seriously probably resulting from the structure instability and the partial dissolution of discharge products in the electrolyte. A modified approach was to design some electrically conducting polymeric organosulfides, which keep conjugated backbones at both oxidation and reduction states and suitable sites of interpolymer disulfide bonds among different polymer chains. Herein, we prepared a novel carbyne polysulfide material containing a conducting carbon skeleton and energy-storing sulfur side chain without other elements 
by coheating carbyne and sulfur. Furthermore, the electrochemical performance of carbyne polysulfide as a novel cathode material for rechargeable magnesium batteries was investigated.

\section{Experimental}

2.1. Preparation of Materials. Carbyne polysulfide material was synthesized by coheating carbyne and sulfur. $20 \mathrm{~g}$ polyvinylidene chloride (PVDC) was slowly added into the mixture of $800 \mathrm{~mL}$ saturated $\mathrm{KOH}$ ethanol solution (25 mass.\%) and $1200 \mathrm{~mL}$ tetrahydrofuran (THF). After reacting under $\mathrm{N}_{2}$ atmosphere for $1 \mathrm{~h}$ at room temperature, the reaction liquid was neutralized with $2 \mathrm{~mol} \mathrm{~L}^{-1} \mathrm{HCl}$ solution. Precipitate was collected by filtration and washed with distilled water and acetone for several times. Black carbyne powder was obtained after drying the precipitate under vacuum at room temperature. Then, the carbyne powder was mixed with sulfur at a molar ratio of $1: 5$ and ball-milled for $1 \mathrm{~h}$. The mixture was heated at different temperatures $\left(150^{\circ} \mathrm{C}, 200^{\circ} \mathrm{C}\right.$, $250^{\circ} \mathrm{C}, 300^{\circ} \mathrm{C}$, and $350^{\circ} \mathrm{C}$ ) at $10^{\circ} \mathrm{C} \mathrm{min}^{-1}$ in a tube furnace, kept at the temperature for $3 \mathrm{~h}$ under a $\mathrm{N}_{2}$ atmosphere, and then allowed to cool to room temperature naturally. The products were marked as S1, S2, S3, S4, and S5, respectively.

2.2. Preparation of Electrolyte. The preparation procedure for the electrolyte solution of $0.25 \mathrm{~mol} \mathrm{~L}^{-1} \mathrm{Mg}\left(\mathrm{AlCl}_{2} \mathrm{EtBu}\right)_{2} / \mathrm{THF}$ was previously reported in detail [16]. Briefly, $\mathrm{MgBu}_{2}$ solution $\left(1 \mathrm{~mol} \mathrm{~L}^{-1}\right.$ in hexane, Aldrich) and $\mathrm{AlCl}_{2} \mathrm{Et}$ solution $\left(0.9 \mathrm{~mol} \mathrm{~L}^{-1}\right.$ in heptane, Aldrich) were mixed at a $1: 2$ ratio at room temperature, which caused a white solid to immediately precipitate. After stirring for $48 \mathrm{~h}$, the solvents (hexane and heptane) were removed by evaporation, and high purity THF (distilled with benzophenone containing sodium chips under an Ar atmosphere) was added to form the desired $0.25 \mathrm{~mol} \mathrm{~L}^{-1}$ solution. All the chemical preparations were performed in an Ar-filled glove box (Mbraun, Unilab, Germany).

2.3. Structural and Morphological Characterization. X-ray powder diffraction (XRD) analysis was performed using a Rigaku D/MAX-2200/PC X-Ray Diffractometer (Japan) equipped with a $\mathrm{Cu} K \alpha$ radiation source $(\lambda=0.15406 \mathrm{~nm})$ to analyze the components of the products. Solid-state ${ }^{13} \mathrm{C} \mathrm{NMR}$ was performed with an Avance III 400 spectrometer (Bruker Inc., Switzerland). Raman spectrum was carried out on a Dispersive Raman Microscope (Senterra R200-L, Bruker Optics, Germany). Thermogravimetric (TG) analysis was performed at a Thermogravimetric Analyzer (TGA 7, Perkin Elmer, Inc., USA) and differential scanning calorimeter (DSC) analysis was performed at a Differential Scanning Calorimeter (Pyris 1, Perkin Elmer, Inc., USA). The elements of the material were analyzed by an inductively coupled plasma-atomic emission spectroscopy (ICP-AES) using an Iris Advantage 1000 spectroscope (Thermo Electron). The microscopic features of the product were observed using scanning electron microscopy (SEM) on a JEOL field-emission microscope (JSM-7401F) and transmission electron microscopy (TEM) on a JEOL high-resolution electron microscope (JEM-2010).
TABLE 1: Elemental analysis result of the products prepared by coheating carbyne and sulfur at different temperatures.

\begin{tabular}{|c|c|c|c|c|c|c|}
\hline \multirow{2}{*}{\multicolumn{2}{|c|}{ Sample Temperature $/{ }^{\circ} \mathrm{C}$}} & \multicolumn{4}{|c|}{ Element content/\% } & \multirow{2}{*}{ Composition } \\
\hline & & \multirow{2}{*}{$\frac{C}{6.23}$} & \multirow{2}{*}{$\frac{\mathrm{H}}{0.64}$} & \multirow{2}{*}{$\frac{\mathrm{Cl}}{0.74}$} & \multirow{2}{*}{$\frac{S}{91.51}$} & \\
\hline S1 & 150 & & & & & $\mathrm{CH}_{1.21} \mathrm{Cl}_{0.04} \mathrm{~S}_{5.40}$ \\
\hline S2 & 200 & 5.91 & 0.77 & 0.75 & 92.41 & $\mathrm{CH}_{1.57} \mathrm{Cl}_{0.04} \mathrm{~S}_{5.89}$ \\
\hline S3 & 250 & 6.47 & 1.11 & 0.51 & 91.60 & $\mathrm{CH}_{2.06} \mathrm{Cl}_{0.03} \mathrm{~S}_{5.30}$ \\
\hline S4 & 300 & 21.94 & 0.94 & 1.15 & 74.49 & $\mathrm{CH}_{0.52} \mathrm{Cl}_{0.02} \mathrm{~S}_{1.28}$ \\
\hline S5 & 350 & 36.10 & 0.87 & 2.09 & 57.13 & $\mathrm{CH}_{0.29} \mathrm{Cl}_{0.02} \mathrm{~S}_{0.59}$ \\
\hline
\end{tabular}

$\mathrm{N}_{2}$ adsorption-desorption experiments were carried out at $-196^{\circ} \mathrm{C}$ on a ASAP $2010 \mathrm{M}+\mathrm{C}$ surface area and pore analyzer (Micromeritics, USA) after degassing of the samples at $200^{\circ} \mathrm{C}$ for 3 hours. The specific surface area of sample was determined by Brunauere-Emmette-Teller (BET) measurement with nitrogen gas on an ASAP $2010 \mathrm{M}+\mathrm{C}$ surface area analyzer (Micromeritics, USA).

2.4. Electrochemical Measurements. 75 wt.\% carbyne polysulfide active material, 15 wt.\% super-P carbon powder, and 10 wt.\% poly(vinylidene fluoride) (PVDF) dissolved in $\mathrm{N}$ methyl-2-pyrrolidinone (NMP) were mixed and coated onto a copper foil with a typical thickness of $50 \mu \mathrm{m}$. After volatilization of the solvent, the coated current collector was punched into $12 \mathrm{~mm}$ diameter disks, pressed at $3 \mathrm{MPa}$, and dried at $80^{\circ} \mathrm{C}$ for $10 \mathrm{~h}$ under vacuum to form electrode disks loaded with active materials. Cyclic voltammetry (CV) measurement was conducted via a three-electrode cell on a CHI650C electrochemical workstation (CH Instruments Inc., USA). The working electrode had the same composition as mentioned above, magnesium ribbon ( $1 \mathrm{~mm}$ diameter) (Aldrich) acted as both the reference and counter electrode, and $0.25 \mathrm{~mol} \mathrm{~L}^{-1} \mathrm{Mg}\left(\mathrm{AlCl}_{2} \mathrm{EtBu}\right)_{2} / \mathrm{THF}$ as the electrolyte. The electrochemical performance of the active material was further examined via CR2016 coin cells with a magnesium ribbon counter electrode, an Entek PE membrane separator. The three-electrode cells and coin cells were assembled in an Ar-filled glove box. Galvanostatic charge-discharge measurements were conducted on a Land battery measurement system (Wuhan, China) with a cut-off voltage between $1.8 \mathrm{~V}$ and $0.5 \mathrm{~V}$ versus $\mathrm{Mg}$. All the electrochemical tests were performed at room temperature.

\section{Results and Discussion}

The element analysis of products (S1, S2, S3, S4, and S5) prepared by coheating carbyne and sulfur at different temperatures is shown in Table 1 . The main elements are $\mathrm{S}$ and $\mathrm{C}$ with few $\mathrm{H}$ and $\mathrm{Cl}$. The molar ratio of $\mathrm{S}: \mathrm{C}$ for $\mathrm{S} 1, \mathrm{~S} 2$, and S3 is over $5: 1$, which is mainly resulted from little loss of elemental sulfur lower than $250^{\circ} \mathrm{C}$ and the consumption of some carbon with oxygen-containing groups (produced from the reaction of PVDC and $\mathrm{KOH}$ ) in the products. The ratio of S/C decreases to $1.28: 1$ for S4 and $0.59: 1$ for S5 with the increase of heating temperature, indicating the sublimation 


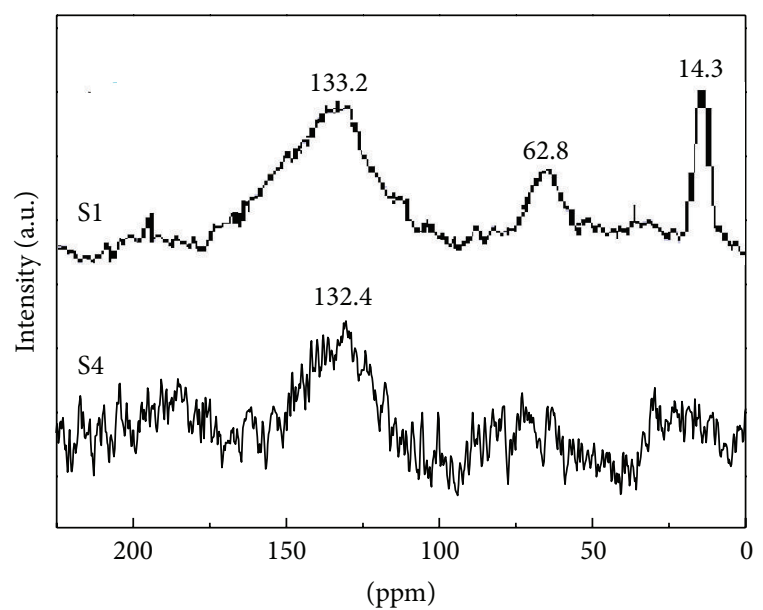

Figure $1:{ }^{13} \mathrm{C}-\mathrm{NMR}$ spectra of S1 and S4.

of most of elemental sulfur at the temperature higher than $300^{\circ} \mathrm{C}$.

Figure 1 shows the solid-state ${ }^{13} \mathrm{C}$ NMR of $\mathrm{S} 1$ and $\mathrm{S} 4$. There is a peak at 133.2 and $132.4 \mathrm{ppm}$ for S1 and S4, respectively. It corresponds to the $\mathrm{sp}^{2}$ hybridization of carbon, suggesting that both $\mathrm{S} 1$ and $\mathrm{S} 4$ contain carbon-carbon double bonds. For S1, two additional peaks at $14.3 \mathrm{ppm}$ and $62.8 \mathrm{ppm}$ are related to $-\mathrm{CH}_{3}$ and sp hybridization of carbon, respectively [17]. It is demonstrated that the product prepared at $150^{\circ} \mathrm{C}$ exhibits a compound structure with triple bonds, double bonds, and $-\mathrm{CH}_{3}$ groups resulting from side reaction. The single peak for $\mathrm{S} 4$ illustrates that the product prepared at $300^{\circ} \mathrm{C}$ has a single structure.

Raman spectrum was further employed to confirm the structure of the products. Figures 2(a) and 2(b) show the Raman spectra of carbyne, which was heat-treated at different temperatures, and the products prepared by coheating carbyne and sulfur at different temperatures. Two peaks appear at about $1368 \mathrm{~cm}^{-1}$ and $1587 \mathrm{~cm}^{-1}$ for carbyne and $1408 \mathrm{~cm}^{-1}$ and $1578 \mathrm{~cm}^{-1}$ for the products. The variation of the ratio of the two peaks with temperature is shown in Figure 3. Compared with that for carbyne, the value for the products increases obviously with the increasing temperature. As a result, the difference of carbon structure between carbyne and the products does not result from the heat treating temperature but the interaction of carbyne with sulfur during the heat treating process. It was reported that the peaks at $1580 \mathrm{~cm}^{-1}$ and $1360 \mathrm{~cm}^{-1}$ can be attributed to the carbon vibration of graphite crystallite at the centers and edges, which were called $\mathrm{G}$ and $\mathrm{D}$ vibration modes, respectively [18]. The peak at $1368 \mathrm{~cm}^{-1}$ for carbyne shifts to $1408 \mathrm{~cm}^{-1}$ after coheating treatment of carbyne and sulfur. It is suggested that the carbon vibration of graphite crystallite at edges is influenced by sulfur. A chemical reaction not the simple mixture occurs between sulfur and carbyne. $I_{1408} / I_{1578}$ increases with the coheating temperature, indicating that the carbon at edges reacts with more sulfur at high temperature. As shown in inset of Figure 2(b), a peak with low intensity appears at $750 \mathrm{~cm}^{-1}$. It can be attributed to C-S bonds [19].

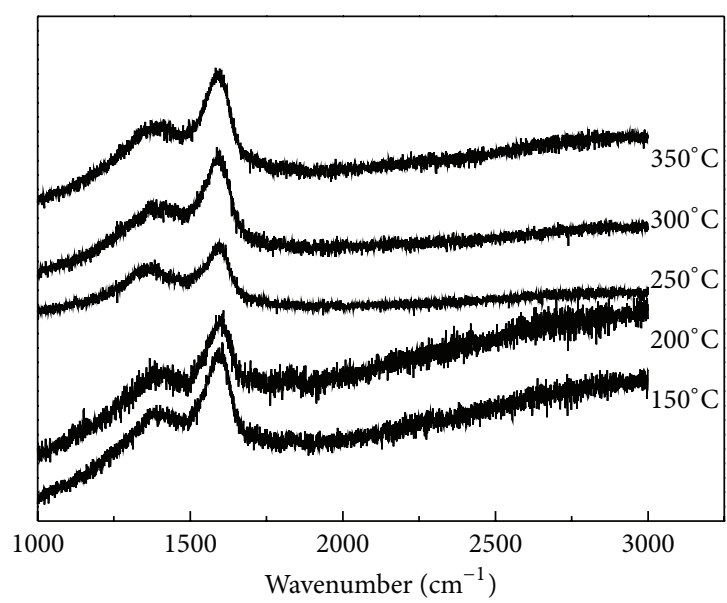

(a)

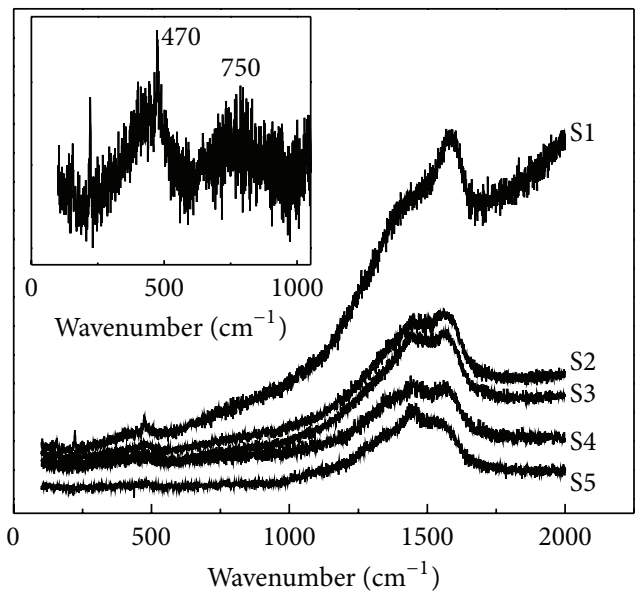

(b)

FIgURE 2: Raman spectrum of (a) carbyne treated at different temperatures, (b) S1, S2, S3, S4, and S5; inset is a partial magnification for the spectrum of $S 4$.

For S1, S2, S3, and S4, there is a peak appearing at $470 \mathrm{~cm}^{-1}$, suggesting the existence of $\mathrm{S}-\mathrm{S}$ bonds. The peak disappears in the spectrum of S5. It is demonstrated that the S-S bonds do not exist in the product when the coheating temperature reaches $350^{\circ} \mathrm{C}$.

The results of TG/DSC (not shown) for the products demonstrate that there are four endothermic peaks at 102.0, $119.3,167.0$, and $333.8^{\circ} \mathrm{C}$ for S1, S2, and S3. The former three and the last are related to crystal phase transition in melting and sublimation of elemental sulfur, respectively. The peaks become weaker for S4 and unobvious for S5. TG analysis of S4 in Figure 4 shows a low weight loss at about $330^{\circ} \mathrm{C}$, suggesting a small amount of elemental sulfur in the material. There is about $60 \%$ and $30 \%$ weight loss at above $400^{\circ} \mathrm{C}$ for S4 and S5, respectively, indicative of a moderate thermal stability due to the chemical combination between sulfur and carbon. XRD pattern shown in Figure 5 further demonstrates that $\$ 4$ mainly contains amorphous carbon with a preferred orientation at (002) lattice plane. 


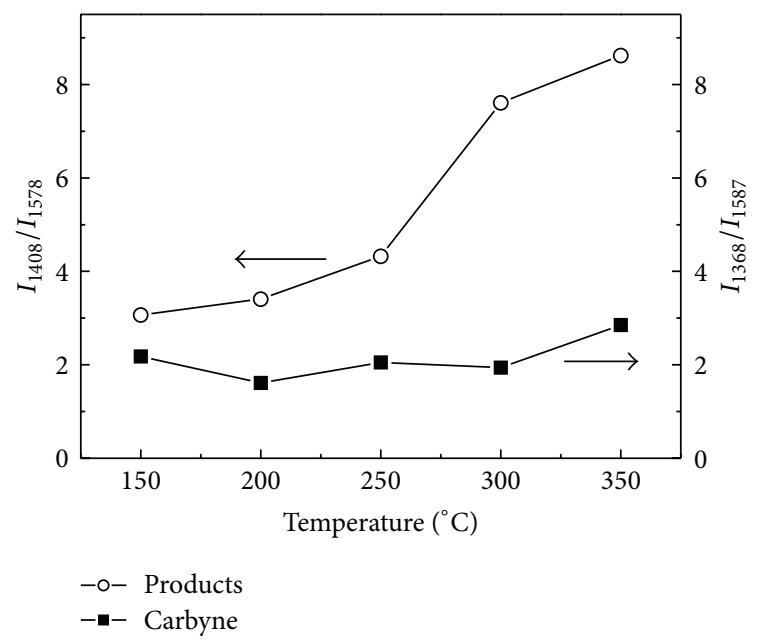

Figure 3: The intensity ratio between vibration modes of products and carbyne treated at different temperatures.

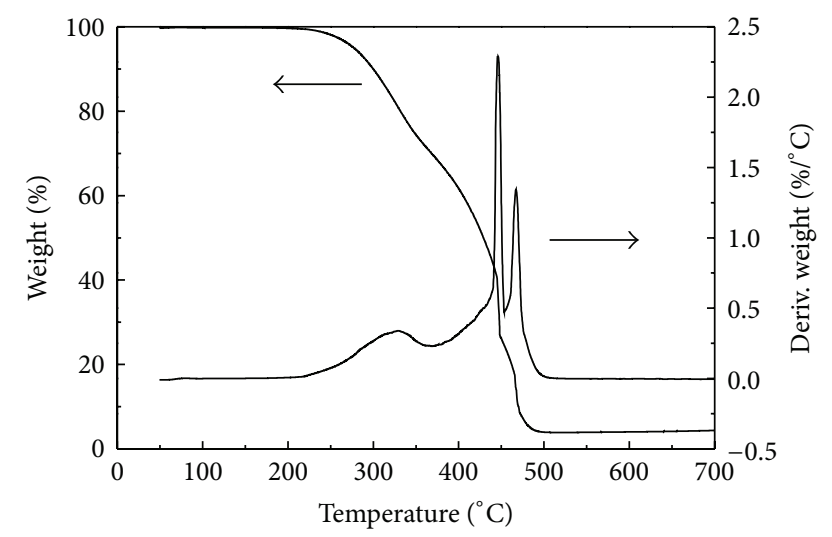

FIgURE 4: TG analysis of S4.

From what has been discussed above, it can be concluded that there is no chemical combination between sulfur and carbon at the coheating temperature lower than $250^{\circ} \mathrm{C}$. When the temperature increases to $300^{\circ} \mathrm{C}$, most of sulfur links in the form of S-S bonds to the carbon matrix with $\mathrm{sp}^{2}$ hybridization. The structure is favorable to provide a conducting carbon skeleton and energy-storing sulfur side chain. However, $\mathrm{S}-\mathrm{S}$ bonds decompose when the temperature reaches $350^{\circ} \mathrm{C}$. The product prepared at $300^{\circ} \mathrm{C}$ (called carbyne polysulfide) was chosen for further electrochemical measurements.

Figures 6(a) and 6(b) show SEM images of carbyne polysulfide with different magnification. The material features nonuniform particles ranged from hundreds of nanometers to a few micrometers. A closer observation (Figure 6(b)) shows that some particles are composed of porous structures. The morphology and microstructure of the material were further investigated by TEM. Figures 6(c) and 6(d) show the typical images with different magnification. The formation of a porous framework with different sizes of pores is clearly

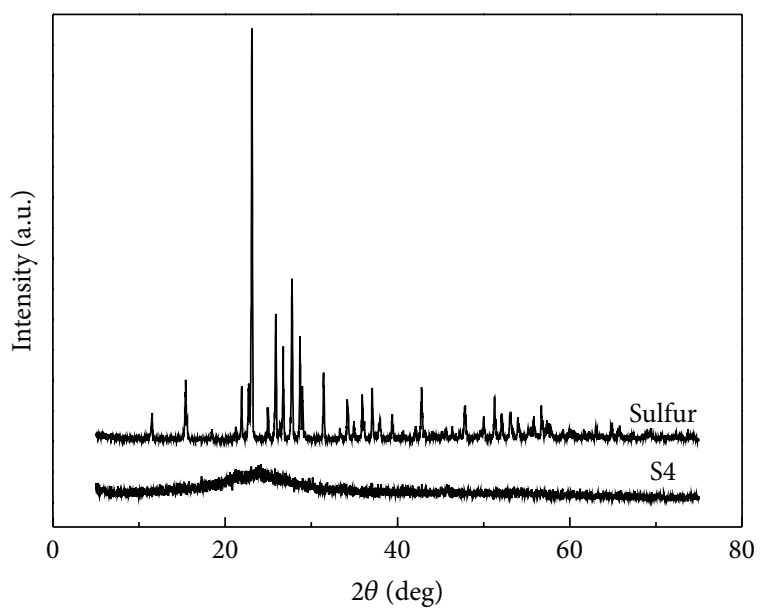

FIGURE 5: XRD patterns of element sulfur and S4.

observed. In this structure, the electrolyte will effectively fill the particles. The porous structure is probably due to the release of large quantity of sulfur vapor during the sintering process.

The porosity of carbyne polysulfide can be further confirmed by nitrogen adsorption-desorption analysis. The nitrogen adsorption-desorption isotherm for carbyne polysulfide is shown in Figure 7. The isotherm is of type II classification with a hysteresis. Type II isotherms are characteristic of multilayer adsorption on nonporous or macroporous solids [20]. Porosity characteristics are more evidently observed from BJH curve (the inset of Figure 7), which reflects the presence of pores of two different sizes. There is a narrow pore-size distribution at approximately $50 \mathrm{~nm}$ and a broad distribution of pores around $120 \mathrm{~nm}$. The specific surface area calculated by the Brunauer-EmmettTeller (BET) method and the pore volume determined by the Barrett-Joyner-Halenda (BJH) approach are $9.7624 \mathrm{~m}^{2} \mathrm{~g}^{-1}$ and $0.099687 \mathrm{~cm}^{3} \mathrm{~g}^{-1}$, respectively.

Cyclic voltammogram (CV) and galvanostatic dischargecharge techniques were used to investigate the electrochemical behavior of the carbyne polysulfide material for electrochemical magnesium storage. Figure 8(a) shows CV curves of carbyne polysulfide in a three-electrode cell employing magnesium metal as the counter electrode and the reference electrode at a scan rate of $0.05 \mathrm{mV} \mathrm{s}^{-1}$. The voltammograms demonstrate two pairs of cathodic/anodic peaks, which are marked as $\mathrm{A} / \mathrm{A}^{\prime}$ and $\mathrm{B} / \mathrm{B}^{\prime}$, respectively. The process can be attributed to the electrochemical reaction of a small amount of elemental sulfur with magnesium and the cleavage and linkage of S-S bonds, respectively. In view of sulfur mainly in the form of $\mathrm{S}-\mathrm{S}$ bonds in the material, the cleavage and recombination of $\mathrm{S}-\mathrm{S}$ bonds formed during reduction and oxidation process is the key components for the electrochemical reaction. It has been reported that the copper current collector can react with $\mathrm{Mg}\left(\mathrm{AlCl}_{2} \mathrm{EtBu}\right)_{2} / \mathrm{THF}$ electrolyte above $1.8 \mathrm{~V}$ [21]. In the CV measurements, the anodic current was observed beginning from $1.8 \mathrm{~V}$ and there was an oxidation peak at $2.05 \mathrm{~V}$, which was ascribed to the electrochemical 


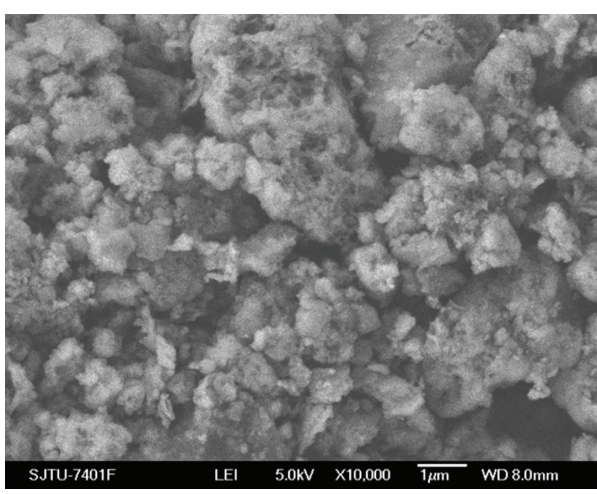

(a)

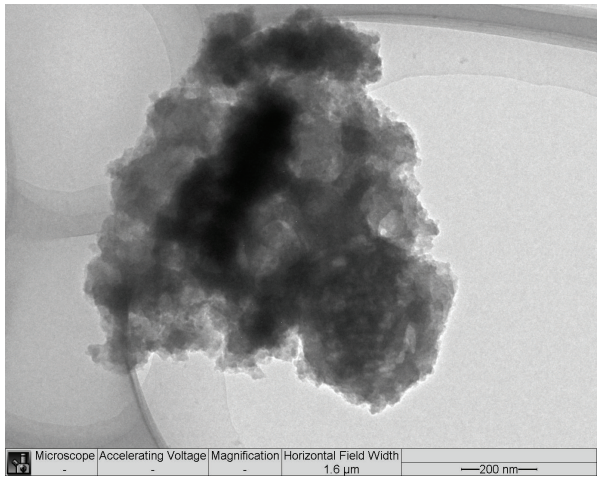

(c)

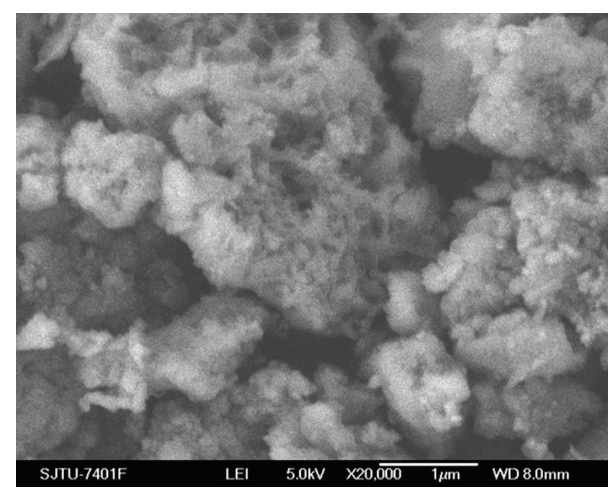

(b)

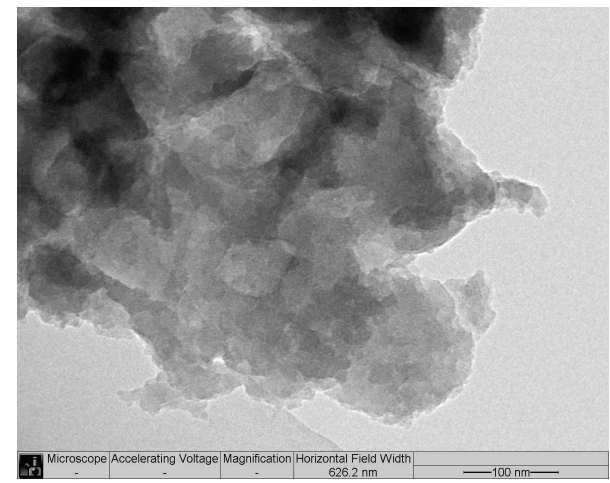

(d)

FIgURE 6: SEM ( $a$ and b) and TEM (c and d) images of carbyne polysulfide.

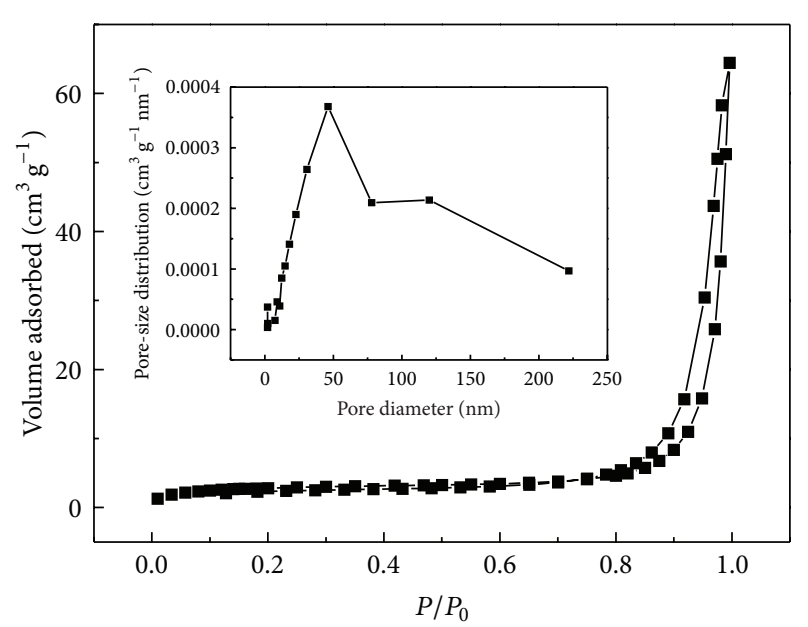

FIGURE 7: Nitrogen adsorption-desorption isotherms of carbyne polysulfide. The inset shows the pore-size distribution.

oxidation of $\mathrm{Cu}$. A reduction peak was observed at about $1.0 \mathrm{~V}$, which may be ascribed to electrochemical reduction of $\mathrm{Cu}^{2+}$ or $\mathrm{Cu}^{+}$to $\mathrm{Cu}$. Considering the possible disturbance of copper collector, the CVs comparison of $\mathrm{Cu}$ substrate and carbyne polysulfide active material on copper collector is shown in Figure $8(\mathrm{~b})$. There are indeed oxidation and reduction processes related to the reaction of copper current collector with the electrolyte when the upper potential limit is over 1.8 V. However, the electrochemical process below $1.8 \mathrm{~V}$ should be related to the reaction of the active material with magnesium.

Figure 9(a) shows a typical discharge and charge curve of carbyne polysulfide in a two-electrode coin cell employing magnesium metal as the counter electrode at a current rate of $3.9 \mathrm{~mA} \mathrm{~g}^{-1}$. The discharge curve demonstrates two separate plateaus of $1.6 \mathrm{~V}$ and $1.1 \mathrm{~V}$ related to the reduction peaks of $\mathrm{B}$ and $\mathrm{A}$ in Figure 8(a). The discharge corresponds to $327.7 \mathrm{mAh} \mathrm{g}^{-1}$ capacity, that is, $53.8 \%$ of the theoretical value $609.1 \mathrm{mAh} \mathrm{g}^{-1}$. The high capacity may be resulted from the special structure of carbyne polysulfide with a conducting carbon skeleton and energy-storing sulfur side chain without other elements. The discharge capacity versus cycle number of carbyne polysulfide at a higher rate of $5.4 \mathrm{~mA} \mathrm{~g}^{-1}$ is shown in Figure 9(b). The material exhibits an activation process during the initial cycles due to the gradual infiltration of electrolyte into the electrode. The slow penetration of electrolyte into the pores and some parasitic reactions occurring on the material also result in an unstable capacity upon cycling. As shown in the figure, the discharge capacity and the cycling performance are not satisfied. It has been concluded that carbyne polysulfide contains a conducting carbon skeleton and energy-storing sulfur side chain, which should keep the discharge products remaining in the skeleton during the cycling process. Further work is aimed at choosing a 


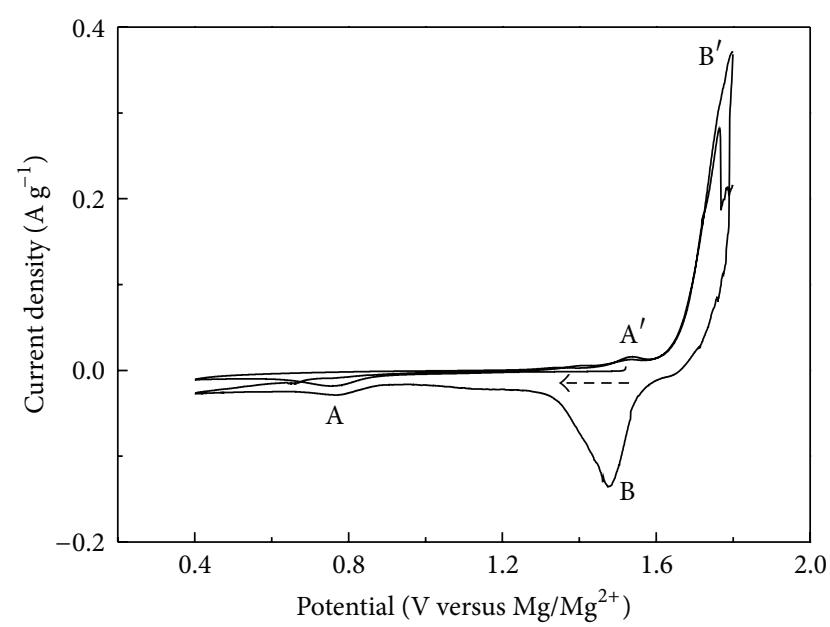

(a)

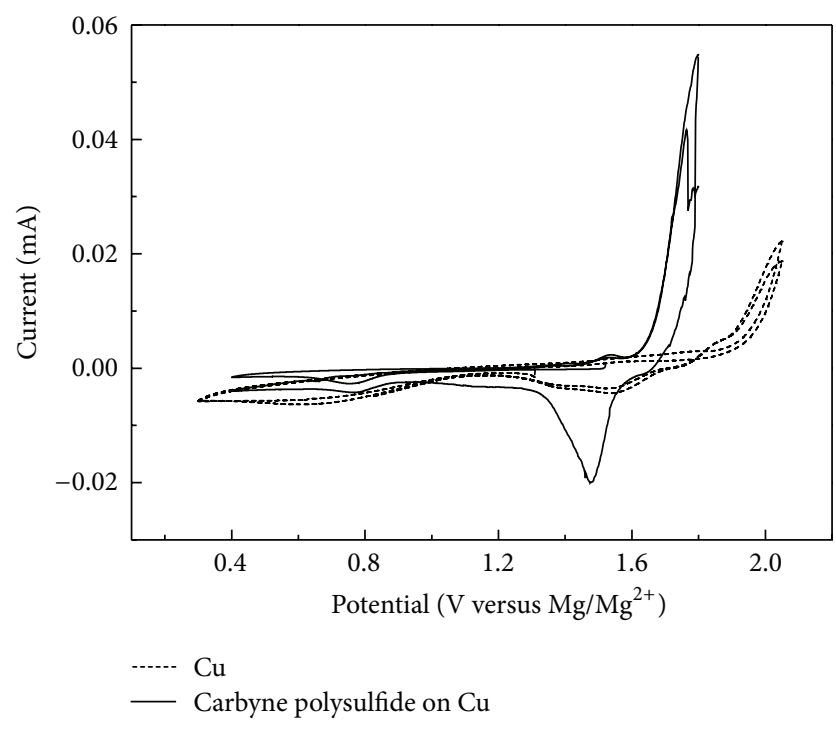

(b)

Figure 8: (a) Cyclic voltammograms of carbyne polysulfide in a three-electrode cell employing magnesium metal as the counter electrode and the reference electrode measured at a scan rate of $0.05 \mathrm{mV} \mathrm{s}^{-1}$. (b) $\mathrm{CV}$ comparisons using $\mathrm{Cu}$ copper collector and carbyne polysulfide on copper collector as positive electrodes. The active mass of carbyne polysulfide was $0.1476 \mathrm{mg}$.

more matchable electrolyte system to improve the capacity retention of carbyne polysulfide.

\section{Conclusions}

Carbyne polysulfide material was prepared by coheating carbon containing carbyne moieties and elemental sulfur. The product was proved to have a $\mathrm{sp}^{2}$ hybrid carbon skeleton with polysulfide attached on it. The structure is favorable to provide a conducting carbon skeleton and energy-storing sulfur side chain. The electrochemical measurements exhibited that carbyne polysulfide can be used as a novel cathode material

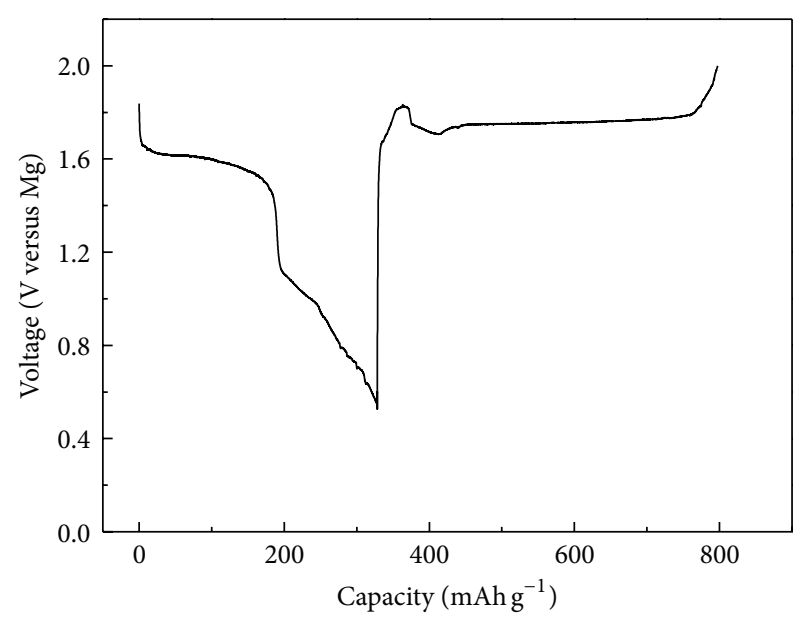

(a)

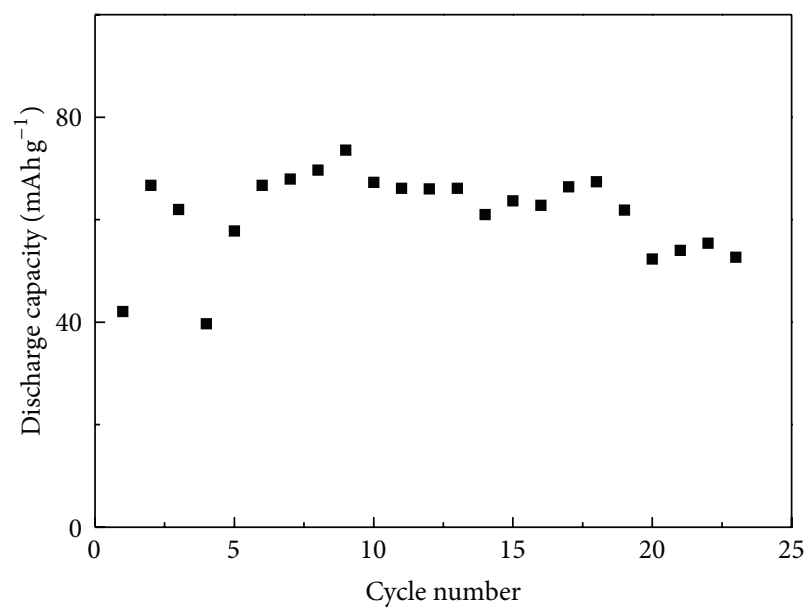

(b)

FIGURE 9: (a) A typical discharge-charge curve of carbyne polysulfide in a two-electrode coin cell employing magnesium metal as the counter electrode at a current rate of $3.9 \mathrm{~mA} \mathrm{~g}^{-1}$. (b) The discharge capacity versus cycle number of carbyne polysulfide in a two-electrode coin cell employing magnesium metal as the counter electrode at a current rate of $5.4 \mathrm{~mA} \mathrm{~g}^{-1}$.

and the material has a high capacity of $327.7 \mathrm{mAhg}^{-1}$ at a current rate of $3.9 \mathrm{mAg}^{-1}$.

\section{Conflict of Interests}

The authors declare that there is no conflict of interests regarding the publication of this paper.

\section{Acknowledgments}

This work was supported by the National Nature Science Foundation of China (Project nos. 20973112 and 21273147), the Shanghai Municipal Science and Technology Commission (Project no. 11JC1405700), and the foundation of Key Laboratory for Thin Film and Microfabrication of the Ministry of Education, Shanghai Jiao Tong University (Project no. B0461-2007-11-004). 


\section{References}

[1] H. S. Kim, T. S. Arthur, G. D. Allred et al., "Structure and compatibility of a magnesium electrolyte with a sulphur cathode," Nature Communications, vol. 2, no. 1, article 427, 2011.

[2] M. Matsui, "Study on electrochemically deposited Mg metal," Journal of Power Sources, vol. 196, no. 16, pp. 7048-7055, 2011.

[3] D. Aurbach, Z. Lu, A. Schechter et al., "Prototype systems for rechargeable magnesium batteries," Nature, vol. 407, no. 6805 , pp. 724-727, 2000.

[4] C. Liebenow, Z. Yang, and P. Lobitz, "The electrodeposition of magnesium using solutions of organomagnesium halides, amidomagnesium halides and magnesium organoborates," Electrochemistry Communications, vol. 2, no. 9, pp. 641-645, 2000.

[5] O. Mizrahi, N. Amir, E. Pollak et al., "Electrolyte solutions with a wide electrochemical window for rechargeable magnesium batteries," Journal of the Electrochemical Society, vol. 155, no. 2, pp. A103-A109, 2008.

[6] J. Muldoon, C. B. Bucur, A. G. Oliver et al., "Electrolyte roadblocks to a magnesium rechargeable battery," Energy and Environmental Science, vol. 5, no. 3, pp. 5941-5950, 2012.

[7] Y. S. Guo, F. Zhang, J. Yang, and F. F. Wang, "Electrochemical performance of novel electrolyte solutions based on organoboron magnesium salts," Electrochemistry Communications, vol. 18, pp. 24-27, 2012.

[8] Q. S. Zhao, Y. N. NuLi, Y. S. Guo, J. Yang, and J. L. Wang, "Reversibility of electrochemical magnesium deposition from tetrahydrofuran solutions containing pyrrolidinyl magnesium halide," Electrochimica Acta, vol. 56, no. 18, pp. 6530-6535, 2011.

[9] E. Levi, Y. Gofer, and D. Aurbach, "On the way to rechargeable $\mathrm{Mg}$ batteries: the challenge of new cathode materials," Chemistry of Materials, vol. 22, no. 3, pp. 860-868, 2010.

[10] Y. L. Liang, R. J. Feng, S. Q. Yang, H. Ma, J. Liang, and J. Chen, "Rechargeable $\mathrm{Mg}$ batteries with graphene-like $\mathrm{MoS}_{2}$ cathode and ultrasmall Mg nanoparticle anode," Advanced Materials, vol. 23, pp. 640-643, 2011.

[11] D. Imamura, M. Miyayama, M. Hibino, and T. Kudo, "Mg intercalation properties into $\mathrm{V}_{2} \mathrm{O}_{5}$ gel/carbon composites under high-rate condition," Journal of the Electrochemical Society, vol. 150, no. 6, pp. A753-A758, 2003.

[12] Y. N. NuLi, J. Yang, Y. S. Li, and J. L. Wang, "Mesoporous magnesium manganese silicate as cathode materials for rechargeable magnesium batteries," Journal of Materials Chemistry, vol. 46, pp. 3794-3796, 2010.

[13] P. Novók, R. Imhof, and O. Haas, "Magnesium insertion electrodes for rechargeable nonaqueous batteries-a competitive alternative to lithium?" Electrochimica Acta, vol. 45, no. 1-2, pp. 351-367, 1999.

[14] M. D. Levi, E. Lancry, H. Gizbar et al., "Kinetic and thermodynamic studies of $\mathrm{Mg}^{2+}$ and $\mathrm{Li}^{+}$ion insertion into the $\mathrm{Mo}_{6} \mathrm{~S}_{8}$ chevrel phase," Journal of the Electrochemical Society, vol. 151, no. 7, pp. A1044-A1051, 2004.

[15] Y. N. NuLi, Z. P. Guo, H. K. Liu, and J. Yang, "A new class of cathode materials for rechargeable magnesium batteries: organosulfur compounds based on sulfur-sulfur bonds," Electrochemistry Communications, vol. 9, no. 8, pp. 1913-1917, 2007.

[16] D. Aurbach, A. Schechter, M. Moshkovich, and Y. Cohen, "On the mechanisms of reversible magnesium deposition processes," Journal of the Electrochemical Society, vol. 148, no. 9, pp. A1004A1014, 2001.
[17] S. E. Evsyukov, S. Paasch, and B. Thomas, "Formation of carbynoid structures by chemical dehydrohalogenation of poly(vinylidene chloride). A ${ }^{13} \mathrm{C}$ solid-state NMR study," Berichte der Bunsengesellschaft für Physikalische Chemie, vol. 101, no. 5, pp. 837-841, 1997.

[18] C. H. Chang, R. A. Beyerlein, and S. S. Chan, "Laser raman investigations of CxS and its related carbons," Carbon, vol. 22, no. 4-5, pp. 393-399, 1984.

[19] Z. Y. Zhu, R. A. Gu, and T. H. Lu, The Application of Raman Spectroscopy in Chemistry, Northeast University Press, Shenyang, China, 1998.

[20] F. Rouquerol, J. Rouquerol, and K. Sing, Adsorption by Powders and Porous Solid: Principles, Methodology, Applications, Academic Press, New York, NY, USA, 1999.

[21] D. P. Lv, T. Xu, P. Saha et al., "A scientific study of current collectors for $\mathrm{Mg}$ batteries in $\mathrm{Mg}\left(\mathrm{AlCl}_{2} \mathrm{EtBu}\right)_{2}$ /thf electrolyte," Journal of The Electrochemical Society, vol. 160, pp. A351-A355, 2013. 

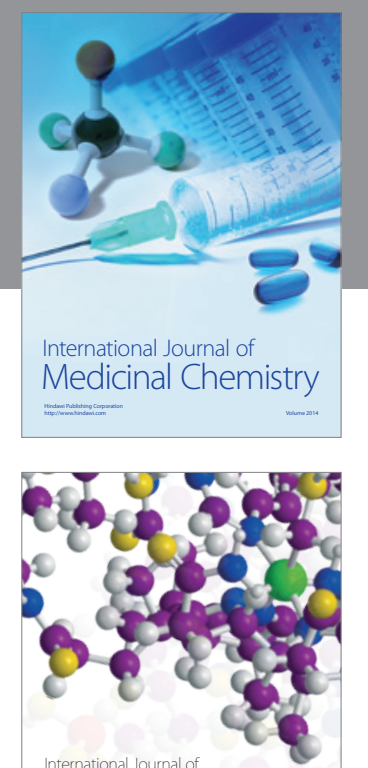

\section{Carbohydrate} Chemistry

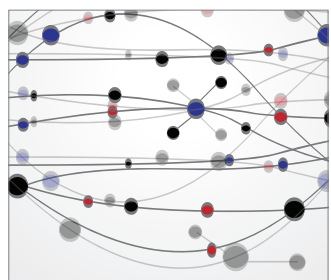

The Scientific World Journal
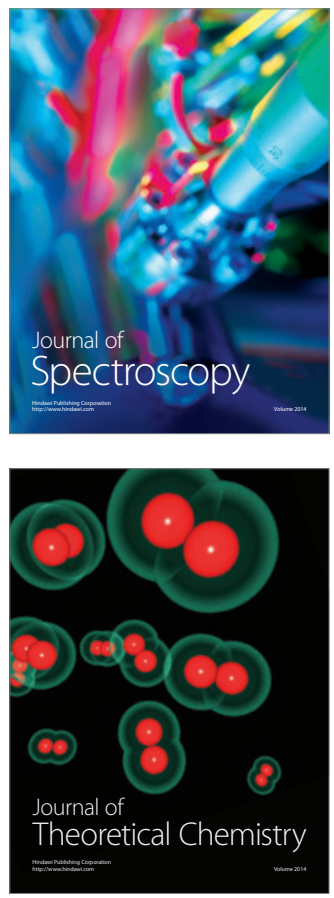
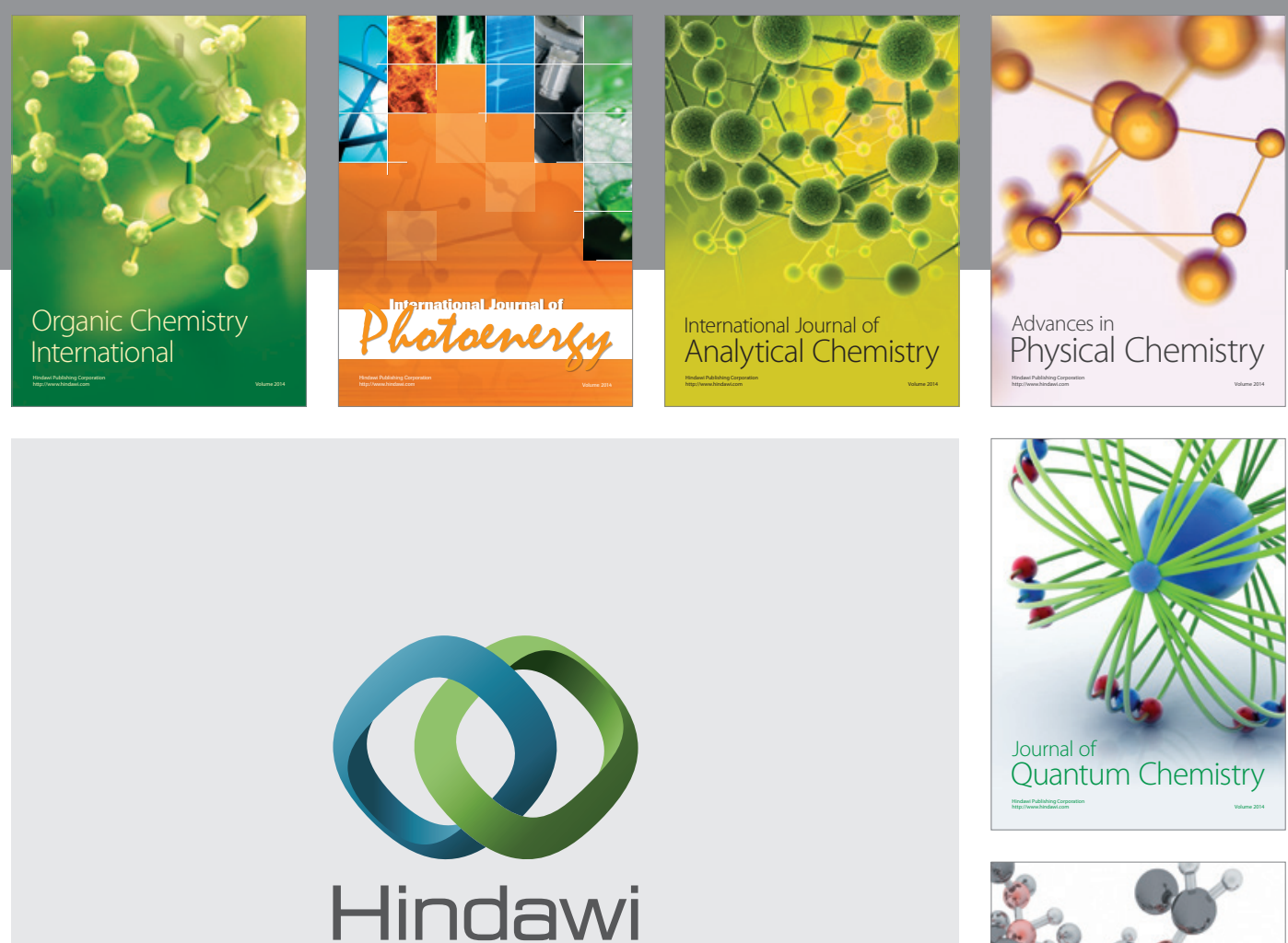

Submit your manuscripts at

http://www.hindawi.com

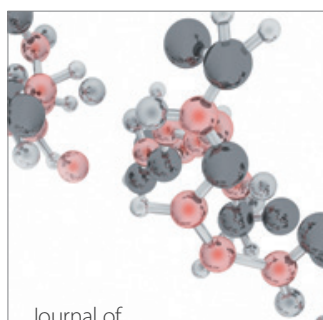

Analytical Methods

in Chemistry

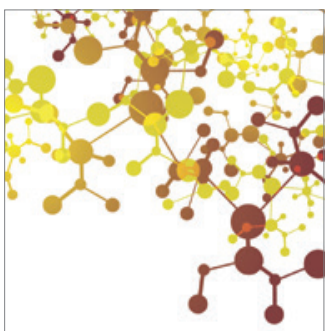

Journal of

Applied Chemistry

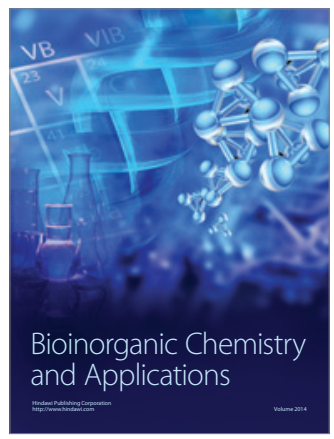

Inorganic Chemistry
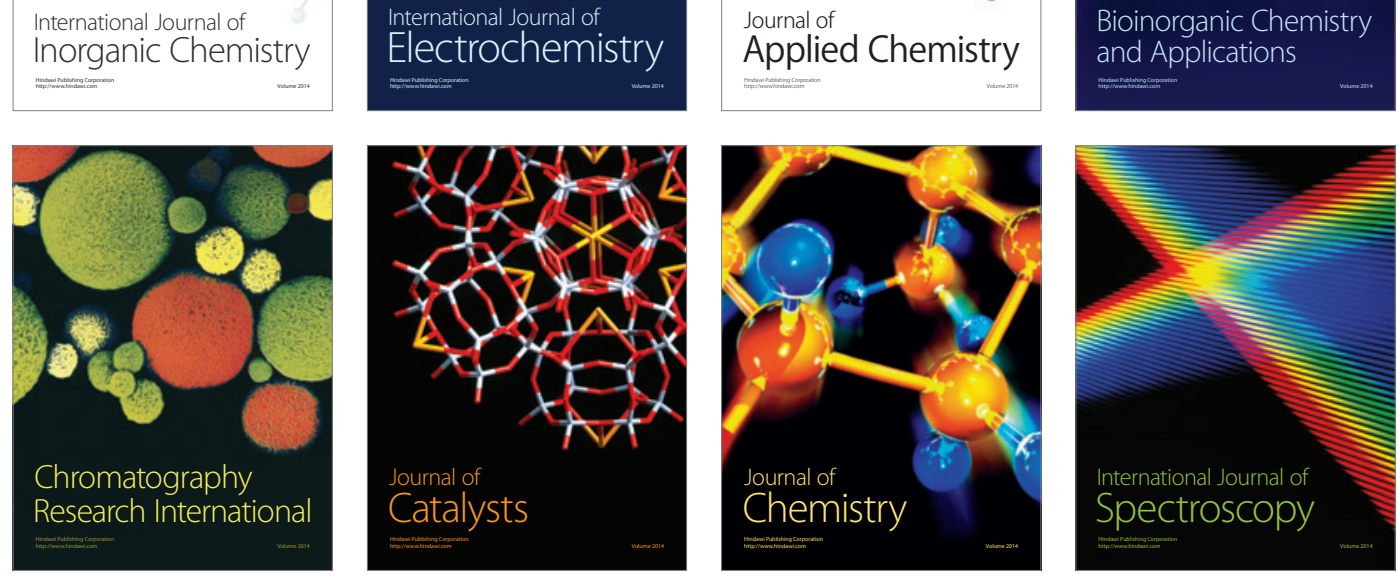